\title{
Transport line for laser multicharged ion source
}

\author{
Md Haider A. Shaim ${ }^{1,2}$, Md Mahmudur Rahman², Oguzhan Balki², Andranik Sarkissian², \\ Michael L. Korwin-Pawlowski ${ }^{4}$, and Hani E. Elsayed-Ali1,2,*
}

\begin{abstract}
The components of a transport line for a laser multicharged ion source are described. Aluminum and carbon multicharged ions are generated by a Q-switched, nanosecond Nd:YAG laser (wavelength $\lambda=1064 \mathrm{~nm}$, pulse width $\tau=7.4 \mathrm{~ns}$, and pulse energy up to $82 \mathrm{~mJ}$ ) ablation of a target in a vacuum chamber. Time-of-flight and a three-grid retarding ion energy analyzers are used to determine the velocity and the charge state of the ions. A three-electrode cylindrical einzel lens is used to focus the ions. At a distance of $30 \mathrm{~cm}$ from the center of the focusing electrode of the einzel lens, $\mathrm{Al}^{1+}$ and $\mathrm{Al}^{2+}$ have a minimum beam diameter of $\sim 1.5 \mathrm{~mm}$, while for $\mathrm{Al}^{3+}$ and $\mathrm{Al}^{4+}$ the minimum beam diameter is $\sim 2.5 \mathrm{~mm}$. The Simulation of the ion trajectories is done using SIMION 8.1. A high voltage pulse applied to a set of two parallel deflecting plates is used for the pickup of ions with different charge states according to their time-of-flight. An electrostatic cylindrical ion deflector is used for analysis and selection of charges with specific
\end{abstract}


energy-to-charge ratio. The design of these transport line components and their operation are described.

Keyword: Multicharged ions, Transport line, Einzel lens.

\section{INTRODUCTION}

Multicharged ion (MCI) sources are emerging tools for nanoprocessing and nanofabrication [1]. The interaction of MCI with a solid is different from that of the singly-charged ion because the total energy of an MCI depends on the potential energy (charge state) and kinetic energy (velocity). The higher charge state $\mathrm{MCI}$ has significant potential energy that is equal to the sum of the ionization energies of stripped electrons. During interaction with a solid, an MCI releases its potential energy along with its kinetic energy. This potential energy causes electronic exchange interaction in the target material and electronic excitation [2]. MCI sources require relatively small acceleration potential because the kinetic energy of the MCIs depends on their charge state. This reduces the requirement on the high voltage power supply making it a comparatively low-cost and compact ion source that can be used for ion implantation. It has been suggested that, because of the ability to control the kinetic and potential energy of the MCIs, the implantation damage by ion recoil can be reduced when using MCIs [3]. For sufficiently slow $\mathrm{MCI}$, the release of this potential energy can be localized on the top few monolayers of the surface and, therefore, can be channeled into the generation of surface nano-features. Surface modification using singly-charged ions may require many particles impinging on the surface site due to a lack of potential energy. The potential energy of the MCI with a high charge state is enough to significantly modify the surface with only a single MCI. The potential energy of the 
MCI is confined to sub-nanoscale, and for ultraslow MCIs can be limited to the top atomic layers making the interaction highly selective to the surface [3].

Among the different ion sources, e.g., electron cyclotron resonance ion sources (ECRIS) [4], electron beam ion sources (EBIS) [5], and laser multicharged ions sources (LMCI) [6, 7], LMCI can be used for ion production directly from solids. Both ECRIS and EBIS operate only with gases and, therefore, for elements with low vapor pressures, they require introducing gaseous compounds or some vaporization mechanism. LMCI can be used to generate MCIs from any solid, even from nonconductive or refractory targets [7, 8]. In LMCI sources, MCIs are generated by focusing a laser pulse on a solid target causing its ablation and ionization. The dense plasma produced consists of ions, electrons, clusters, and neutral particles. The plasma plume expands in a perpendicular direction to the ablated surface. LMCI sources have been tested as potential ion sources for ion injection into ion accelerators [9]. Although ions in the LMCI source are produced from a small spot on the target, the plasma plume is directed mainly perpendicular to the target, limiting ion beam divergence. The produced MCIs can be collimated and focused in an ion transport line by einzel lenses. Ion charge state selection can be done by time-of-flight (TOF) pick-up with parallel deflection plates and ions with a narrow range of energy-to-charge ratio can be selected with electrostatic cylindrical deflectors.

Several groups have reported on the design and operation of ion transport line components. For example, a laser ion source utilizing an Nd:YAG $(\lambda=532 \mathrm{~nm}, \tau=8 \mathrm{~ns}$, repetition rate $20 \mathrm{~Hz}$, and maximum laser energy per pulse $30 \mathrm{~mJ}$ ), Trinczek et al., generated charge state up to $\mathrm{Al}^{4+}$ and focused the charges using a three-electrode einzel lens [10]. A pulsed extraction voltage was used to extract and accelerate the ions. The maximum voltage applied for the pulsed extraction 
and the einzel lens was $30 \mathrm{kV}$ [10]. Yeates et al. reported a laser ion source based on Q-switched Ruby laser $\left(\lambda=532 \mathrm{~nm}, \tau=8 \mathrm{~ns}\right.$, laser fluence of $\left.0.1-3.9 \mathrm{~kJ} / \mathrm{cm}^{2}\right)$ to generate charge state up to $\mathrm{Cu}^{6+}$. Einzel lenses were utilized to transport and collimate the ion beam, which was detected by a Faraday cup [11]. Nagaya et al. reported on an ECRIS to generate fullerene up to a charge state of $\mathrm{C}_{60}{ }^{3+}$. The transport line consisted of three electrode extraction system, einzel lens, analyzing magnet, slit assembly, and Faraday cup [12].

We previously reported on the development of a LMCI and a spark-coupled LMCI source $[13,14]$. Here, we discuss the design and operation of transport line components used in the LMCI source. These components are: (1) A time-of-flight (TOF) ion energy analyzer combined with a three-grid retarding field analyzer used to resolve the various charge states and analyze their energy distributions; (2) Three-electrode electrostatic einzel lens used to focus the MCIs; (3) A set of parallel deflection plates used with a pulsed high-voltage source for MCI pick up based on their TOF; and (4) An electrostatic cylindrical deflector ion energy analyzer (EIA) for MCI selection with energy-to-charge $E / z$ ratio. The EIA selects ions according to the $E / z$ ratio from an MCI beam and allows measuring the energy distribution of each charge state. Ion trajectory simulations are done to design transport line components compatible with our experimental conditions and for better understand the operations of the designs. These simulations are carried out utilizing SIMION 8.1 ion optics software [15].

\section{EXPERIMENTAL SETUP}

Two LMCI sources are constructed, one is used to produce aluminum MCIs while the other is used for carbon MCIs. The transport line components in both systems are similar. A schematic of the MCI source used for the aluminum source is shown in Fig. 1. A Q-switched Nd:YAG laser 
pulse (wavelength $\lambda=1064 \mathrm{~nm}$, pulse width $\tau=7.4 \mathrm{~ns}$ (full-width at half maxima (FWHM)), pulse energy $82 \mathrm{~mJ}$ on target, with maximum repetition rate of $10 \mathrm{~Hz}$ ) is used to ablate the $\mathrm{Al}$ target. An aluminum disc target of area $\sim 1 \mathrm{~cm}^{2}, 99.9 \%$ purity, $0.5 \mathrm{~mm}$ thickness and with a surface roughness (rms) of $261.77 \mathrm{~nm}$, as characterized by the manufacturer (Alfa Aesar), is placed on a multi-axes translational stage. The laser beam is incident on the Al target surface at an angle of $\vartheta=45^{\circ}$. A $50 \mathrm{~cm}$ focal length convergent lens is used to focus the laser beam on the Al surface. The laser spot area at focus is $\sim 0.0024 \mathrm{~cm}^{2}$, as measured by the knife-edge method with the edge scanned at $45^{\circ}$ to the laser beam. Throughout the experiment, the $\mathrm{Al}$ target is biased at $7 \mathrm{kV}$. The distance from the target to mesh is $10 \mathrm{~cm}$ and from the center of the target to the chamber wall is $15 \mathrm{~cm}$. This experimental chamber was described in our recent publications $[13,14]$. The transport line consists of an einzel lens to focus the ion beam, a pair of deflection plates to select ion charge, a knife edge to measure the ion beam diameter and a Faraday cup (FC) to collect the ions. The distance from the $\mathrm{Al}$ target to the center of the middle electrode of the einzel lens is $\sim 94 \mathrm{~cm}$; the knife edge is placed $\sim 30 \mathrm{~cm}$ away from the center electrode of the einzel lens. The deflection plates are at a distance of $\sim 120 \mathrm{~cm}$ away from the $\mathrm{Al}$ target and the FC is at a distance of $33 \mathrm{~cm}$ from the deflection plates. The distance from the $\mathrm{Al}$ target to the $\mathrm{FC}$ is $\sim 153 \mathrm{~cm}$. An EIA can be added before the retarding filed MCI analyzer. The EIA allows for the selection of ions with $E / z$ ratio from an ion beam and can also be used to measure the energy distribution of each charge state. The ion energy distribution can also be obtained from the TOF signal. 


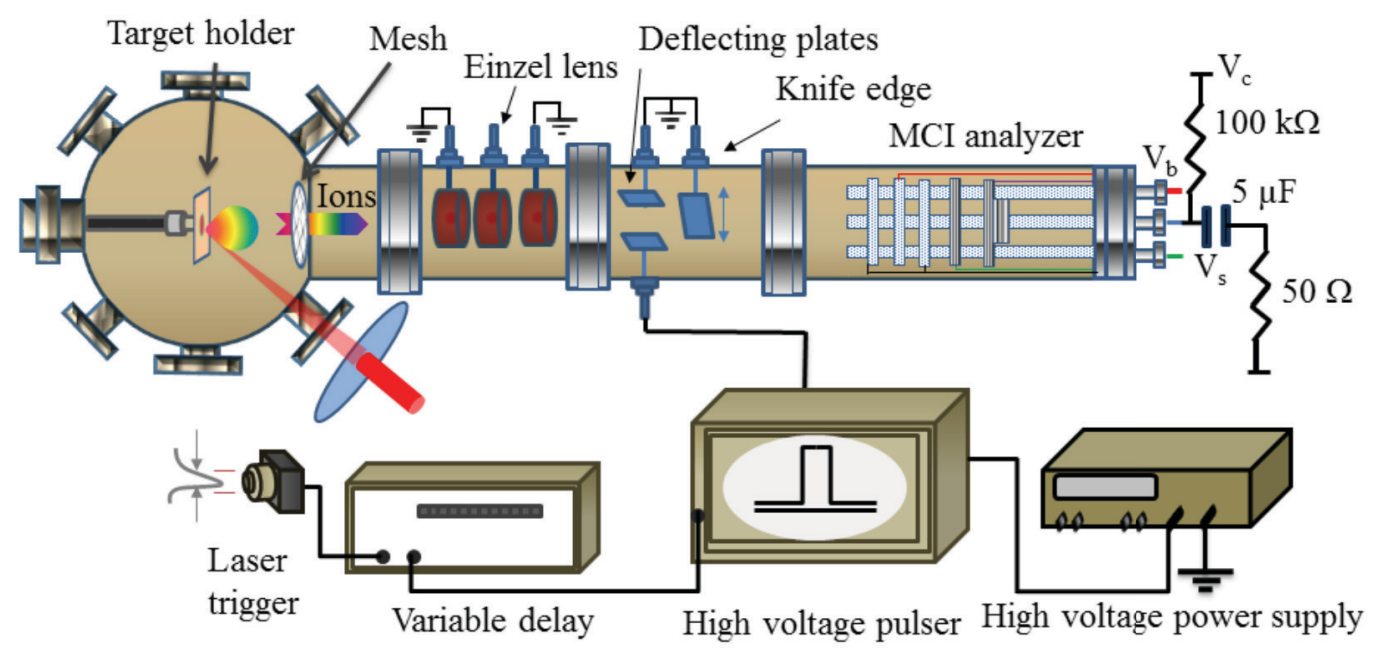

FIG. 1. A schematic of the laser MCI source showing the target chamber, $V_{c}$ is the Faraday cup voltage, and $V_{s}$ is the suppressor voltage, and $V_{b}$ is the barrier voltage.

\section{DESIGN AND OPERATION OF THE TRANSPORT LINE COMPONENTS}

\subsection{Faraday cup and three-electrode retarding field analyzer}

A time-of-flight energy-to-mass $E / m$ analyzer consists of a drift tube terminated by a Faraday cup (FC) with secondary electron suppressor electrode (SE). A three-grid retarding field ion energy analyzer (RIA) is used to analyze the energy of the MCIs. The FC and the SE are made out of aluminum and have a diameter of $5 \mathrm{~cm}$. The RIA consists of three nickel mesh with a diameter of $5 \mathrm{~cm}, 100 \mu \mathrm{m}$ thickness and $70 \%$ opening area, separated by $1 \mathrm{~cm}$ and placed with the closest mesh to aluminum target at a distance of $143 \mathrm{~cm}$. The outer two electrodes of the RIA are grounded while a variable positive voltage is applied to the center electrode to measure the energy distribution of the ions. The effect of voltage on the RIA was recently discussed [13]. The FC, SE and the retarding field ion energy analyzer are placed on a 6 inch $\mathrm{CF}$ flange attached to 
the end of the drift tube. Fig. 2(a) shows a schematic of the FC with suppressor electrode connected to the three-electrode retarding field analyzer. A negatively biased suppressor electrode is used to suppress the signal from secondary electrons due to ion bombardment of the FC. The suppressor electrode keeps the electrons from leaving the FC. We applied $-70 \mathrm{~V}$ to the Faraday cup. By applying a variable negative voltage to the suppressor electrode, starting from ground potential, while observing the shape of the ion signal, we can detect the voltage needed to suppress the effect of secondary electrons. The time-of-flight signal is affected by the secondary electron emission for up to $-70 \mathrm{~V}$ applied to the suppressor electrode. That effect is reduced as we increase the negative voltage applied to the suppressor. At $-80 \mathrm{~V}$, there is no effect due to secondary electron emission. With more negative voltage applied to the suppressor, the shape of the ion signal does not change. In our experiment, we use $-140 \mathrm{~V}$ for the suppressor voltage. Fig. 2(b) shows the effect of suppressor voltage for $-40,-60$, and $-90 \mathrm{~V}$, respectively. The TOF signal shown is for $82 \mathrm{~mJ}$ laser energy on target and no acceleration voltage applied.

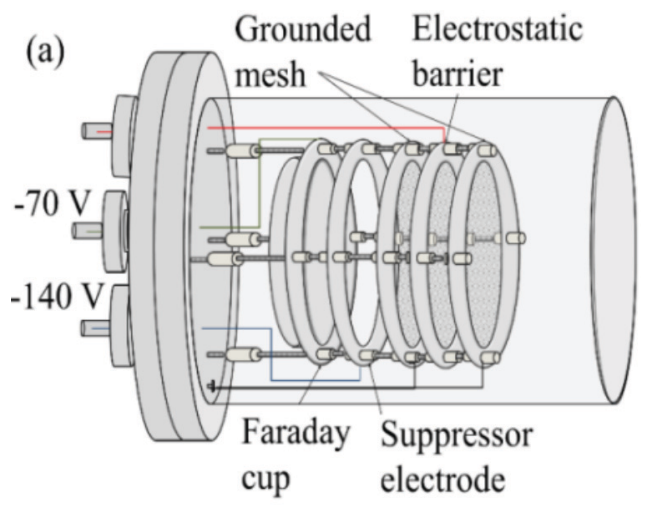




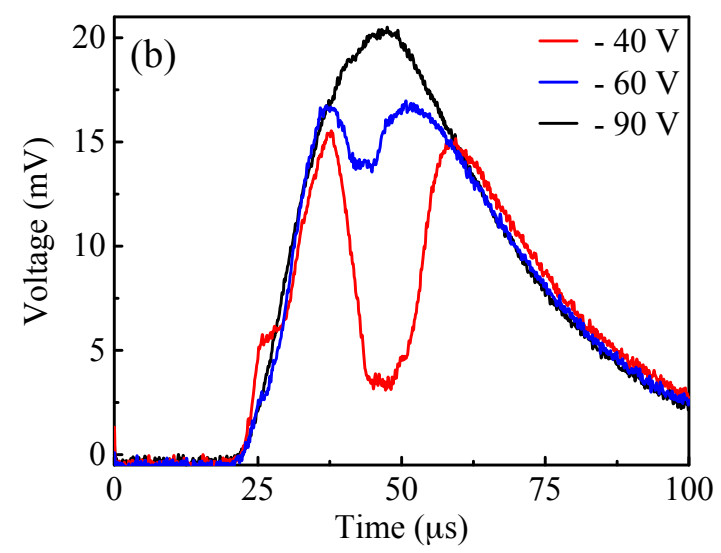

FIG. 2. (a) Schematic of the TOF mass-spectrometer, (b) TOF spectrum for suppressor voltage of $-40,-60$, and $-90 \mathrm{eV}$.

The total charge delivered to the Faraday cup $Q_{i}$ is given by, where $V_{F}(t)$ is the voltage applied to the Faraday cup and $R_{L}$ is the $50 \Omega$ internal resistance of the oscilloscope. Fig. 3(a) shows the MCI signal with charge state up to $\mathrm{Al}^{4+}$ for accelerating voltage of $7 \mathrm{kV}$ and laser pulse energy on target of $82 \mathrm{~mJ}$. A fast positive signal is observed due to the photoelectric effect where photons generated from the laser plasma with energy above the work function of the FC material cause photoemission. The extracted ions from the plasma plume by the electric field between the target and the grounded mesh are detected by their TOF signal measured by the FC. An ion generated at the target with zero energy would reach the FC after a time-of-flight, where is the time that an ion is accelerated from zero velocity at target to velocity at the extraction mesh, is the time that ions drift at constant velocity from the extraction mesh to the FC, $d$ is the distance from the target to the extraction mesh, $S$ is the distance from the extraction mesh to the FC, $m$ is the mass of $\mathrm{Al}$ atom, $e$ is the electron charge, $Z$ is the charge state, and $V$ is the applied accelerating voltage. The above equation does not account for plasma ion shielding, voltage drop on target, and ion acceleration in the expanding plasma. The ion accelerating time is small 
compared to the ion drift time. The procedure to determine the charge state of the ions using their TOF was previously discussed $[13,14]$. The process followed for deconvolution of the total TOF spectrum in Fig. 3(a) into separate ion charges is accomplished by, first, assigning a curve fit to the TOF signal using the peak fitting option in Origin-lab 9.1 software. Then, the TOF signal for each charge is separated using the selected peak position obtained by Origin-lab. Integrating over the time range and dividing the integral by the $50 \Omega$ terminal resistance of the oscilloscope gives the total charge for each charge state delivered to the FC. The signal observed by the FC is the sum of these separated ion signals. The energy distribution for each charge state is calculated for the selected peak position. Peak position selection for the TOF signal corresponding to each charge can be also obtained directly from the TOF signal without curve fitting. These two approaches give almost similar total charge (within 5\%) and energy distribution for each charge state.

The total charge reaching the $\mathrm{FC}$ is $\sim 640 \mathrm{pC}$ when no einzel lens voltage is applied. Fig. 3(b) shows the energy distribution of the MCIs calculated from the TOF signal of the ions. For $\mathrm{Al}^{+1}$, we detect $\sim 150 \mathrm{pC}$ charge per pulse with most probable energy $E_{m p} \sim 2.8 \mathrm{keV}, \sim 180 \mathrm{pC}$ for $\mathrm{Al}^{+2}, E_{m p} \sim 5.5 \mathrm{keV}, \sim 260 \mathrm{pC}$ for $\mathrm{Al}^{+3}, E_{m p} \sim 8.2 \mathrm{keV}$ and $\sim 50 \mathrm{pC}$ for $\mathrm{Al}^{+4}, E_{m p} \sim 11 \mathrm{keV}$. The peak ion currents are $55 \mu \mathrm{A}$ for $\mathrm{Al}^{1+}, 103 \mu \mathrm{A}$ for $\mathrm{Al}^{2+}, 150 \mu \mathrm{A}$ for $\mathrm{Al}^{3+}$ and $100 \mu \mathrm{A}$ for $\mathrm{Al}^{4+}$. The ion energy depends on the plasma parameters, the potential applied to the target, and the shielding effect of the laser plasma. The ion energy distribution is calculated from the ion kinetic energy , where the velocity $v$ is measured from the TOF signal of the MCIs. 

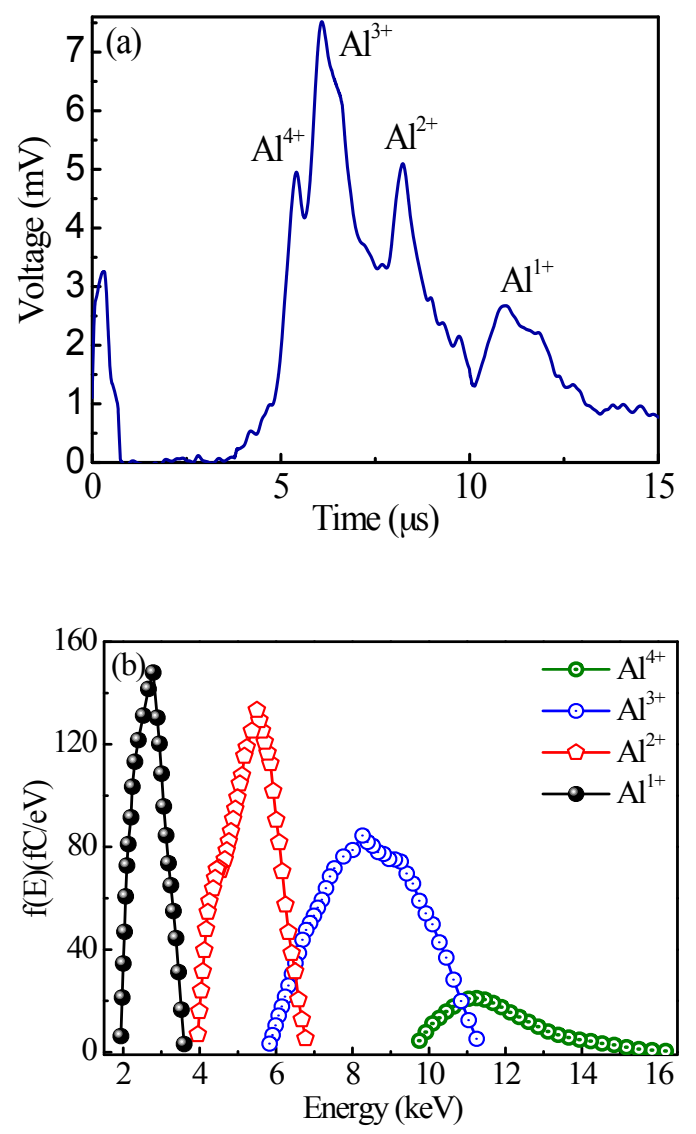

FIG. 3. (a) Time-of-flight analyzer signal for MCIs generating up to $\mathrm{Al}^{4+}$ for $7 \mathrm{kV}$ accelerating voltage and $82 \mathrm{~mJ}$ laser energy on target, (b) energy distribution of the MCIs.

The average current that the described laser MCI source can deliver depends on the laser pulse repetition rate and the current rating of the power supply providing high voltage bias to the target. Due to their higher velocity, the ions pass the grounded grid before the expanding plasma. As the expanding plasma plume from the target reaches the grounded grid, the high voltage power supply is connected to the ground potential through the plasma resistance. This resistance can be low resulting in a drop in power supply voltage. In our system, the Q-switched Nd:YAG laser used has a maximum repetition rate of $10 \mathrm{~Hz}$, while the power supply limits the repetition rate to $\sim 5 \mathrm{~Hz}$ due to time required for the voltage to recover after each pulse. At $5 \mathrm{~Hz}$ operation, 
the average current for each charge states are $\sim 0.75 \mathrm{nA}$ for $\mathrm{Al}^{1+}, \sim 0.9 \mathrm{nA}$ for $\mathrm{Al}^{2+}, \sim 1.3 \mathrm{nA}$ for $\mathrm{Al}^{3+}$, and $\sim 0.25 \mathrm{nA}$ for $\mathrm{Al}^{4+}$.

One application of the Al LMCI source is in implantation of SiC to form a $p$-type layer. Saks et al., implanted $\mathrm{SiC}$ with $30-\mathrm{keV} \mathrm{Al}$ ions to a dose of $\sim 4 \times 10^{11}$ ions $/ \mathrm{cm}^{2}$ [16]. The implant layer doping was $1 \times 10^{17}$ ions $/ \mathrm{cm}^{3}$ with thickness (box profile) of $500 \mathrm{~nm}$. At $\sim 5 \mathrm{~Hz}$ repetition rate, our LMCI source can provide a dose rate of $\sim 5 \times 10^{8}$ ions $/\left(\mathrm{cm}^{2} . \mathrm{s}\right)$ for an ion beam area of $\sim 20 \mathrm{~cm}^{2}$ obtained without focusing. Therefore, a $\mathrm{SiC}$ wafer of $\sim 20 \mathrm{~cm}^{2}$ area can be implanted with $\mathrm{Al}$ MCI to form a shallow $p$-doped layer in $\sim 2.8$ hour. This dose can be further increased by implanting before the ions pass the three meshes of the retarding ion energy analyzer which combined allows only $\sim 34 \%$ of the ions to pass to the Faraday cup.

The ion yield and charge state from laser sources vary widely depending on the laser source and irradiation conditions [17]. Using a table-top femtosecond Ti:sapphire laser (wavelength $\lambda=$ $800 \mathrm{~nm}$, pulse width $\tau=200 \mathrm{fs}$, pulse energy up to $0.5 \mathrm{~mJ}$, and repetition rate $1 \mathrm{kHz}$ ), it was possible to generate up to $\mathrm{Si}^{12+}$ and $\mathrm{W}^{26+}$ with maximum energies in the $\mathrm{keV}$ range per charge state $[18,19]$. An $\mathrm{XeCl}$ excimer $(\lambda=308 \mathrm{~nm}, \tau=20 \mathrm{~ns})$ laser based MCI source was developed and extensive studies on the characteristic of the produced MCI was reported [20, 21]. Ablation of $\mathrm{Cu}$ target using $70 \mathrm{~mJ}\left(56 \mathrm{~J} / \mathrm{cm}^{2} 3.5 \times 10^{8} \mathrm{~W} / \mathrm{cm}^{2}\right)$ laser energy per pulse, maximum charge state generation was $\mathrm{Cu}^{5+}$, with the vast majority of ions singly and doubly ionized and $16 \%$ ionization of the plasma [20,21]. An Nd:YAG (wavelength $\lambda=1064 \mathrm{~nm}$, pulse width $\tau=7 \mathrm{~ns}$, and laser fluence of 10-110 J.cm ${ }^{-2}$ ) was used to produce carbon MCI up to charge state $\mathrm{C}^{4+}$ with the total maximum charge was $\sim 25 \mathrm{nC}$ [22]. 
Electron cyclotron ion sources (ECRIS) and electron beam ion sources (EBIS) generate MCI from gases or external ion or laser ablation sources [23-26]. An ECR ion source operating at $18 \mathrm{GHz}$ microwave of power $1.6 \mathrm{~kW}$ generated $560 \mu \mathrm{A}^{\circ} \mathrm{O}^{7+}, 620 \mu \mathrm{A}$ of $\mathrm{Ar}^{11+}, 430 \mu \mathrm{A}$ of $\mathrm{Ar}^{12+}, 430 \mu \mathrm{A}$ of $\mathrm{Xe}^{20+}[23]$. A maximum current of $1.42 \mathrm{~mA} \mathrm{Ar}{ }^{12+}$ and $1.1 \mathrm{~mA} \mathrm{Xe}{ }^{26+}$ was reported for an ECRIS operating at $24 \mathrm{GHz}$ with $7 \mathrm{~kW}$ power [24]. Production of currents at the $\mathrm{mA}$ level (10 $\mu$ s pulse length) of different ion charges was reported for an EBIS equipped with 5 T, 2-m long and $204 \mathrm{~mm}$ diameter warm bore superconducting solenoid magnet and electron gun operating at $10 \mathrm{~A}$. This EBIS can produce high charge state ions of practically any species, however, it was mainly used to generate $\mathrm{Au}^{32+}$ and $\mathrm{Fe}^{20+}[25]$. An EBIT with $5 \mathrm{~T}$ magnetic field, $800 \mathrm{~mA}$ electron beam current, and $200 \mu \mathrm{m}$ electron beam radius was able to produce $\operatorname{Ar}^{17+}$ [26]. Commercial ECRIS made by Pantechnik operate in a continuous mode [4]. When using superconducting magnets, they can produce high continuous current, e.g., ECRIS model Supernannogan can generate $200 \mu \mathrm{A} \mathrm{C}^{4+}$ [4]. The EBIS are generally pulsed (10-300 Hz), although they can operate in a continuous mode with a low ion yield. For example, DREEBIT EBIS can produce $2 \times 10^{6} \mathrm{C}^{6+}$ ions/pulse [5]. The laser MCI sources produce plasma plume by laser ablation and ionization of a solid target. The ion yield from LMCI sources vary significantly with the laser source used. LMCI sources are mostly experimental and have not been so far commercialized. The availability of many pulsed laser deposition (PLD) systems makes the development of LMCI systems for labs equipped with PLD relatively straightforward, with mainly the ion transport line components needed. The laser MCI system and its transport line can operate in ultrahigh vacuum with a relatively small pumping capacity since no gas load is handled and no differential pumping is needed. High ion yield per laser pulse can be 
generated. With a relatively small Nd:YAG laser (wavelength $1064 \mathrm{~nm}, 15 \mathrm{~ns}$ pulse width, 400 $\mathrm{mJ}$ pulse energy), it is possible to generate $\sim 8 \times 10^{9} \mathrm{C}^{6+}$ ions/pulse [27].

\subsection{Einzel lens}

A three electrode electrostatic einzel lens is used to focus the MCIs. An einzel lens is a three-element lens with the outer two electrodes held at the same potential (in our case grounded), while the central electrode is held at a potential that can be varied for focusing at different distances. This lens does not vary the energy of the charged particles. Several groups reported on the simulation and analytical solutions of charged particle trajectory in einzel lenses. Sise et al., modeled multi-element cylindrical electrostatic lenses for focusing and controlling charged particles. Numerical modeling was done using SIMION [15] and LENSYS [28], and the results were described in terms of the ratios of the electrode lengths and gaps, and the ratios of the controlling voltages [29]. For three, four, and five cylindrical electrode lenses, higher voltage ratios for middle electrodes were shown to result in the lowest spherical and chromatic aberration coefficients [30]. Abdelrahman used SIMION to design a three electrode einzel lens system for focusing $5 \mathrm{keV}$ singly-charged oxygen ions [31]. Different lens parameters were investigated with and without space-charge effects [31]. For $40 \mathrm{~mm}$ aperture diameter lens separated by 20 $\mathrm{mm}$ gaps, the best focal length was $550 \mathrm{~mm}$ from the end of the lens, which was achieved for an applied voltage of $-4.5 \mathrm{kV}$ [31]. An analytical method to evaluate the potential and the fields for a particular cylindrical einzel lens was described and the solution compared well to SIMION modeling [32]. We describe the construction and testing of a three-electrode einzel lens for MCI focusing. 


\subsubsection{Fabrication}

Fig. 4 shows the schematic of the einzel lens consisting of three electrodes of which the outer two electrodes are grounded and the ion beam focusing is done by varying the voltage on the center electrode. These electrodes are made out of stainless steel tubes of $33 \mathrm{~mm}$ length and $43 \mathrm{~mm}$ inside diameter and separated by $\sim 1 \mathrm{~cm}$. A high voltage power supply provides variable negative voltage to the central electrode of the einzel lens. The grounded knife edge, shown in Fig. 1, has a dimension of $5 \times 5 \mathrm{~cm}$ and can be move up and down by an external linear feedthrough to intercept the ion beam path to the FC. The ion beam diameter delivered to the FC is measured with the knife-edge intersecting the ions beam from a fully open position, through the beam, to the position where the beam is fully blocked. The TOF signal of different MCIs are observed and used to calculate MCI transmission at certain knife-edge positions. The number of ions reaching the FC with respect to knife-edge position is plotted. The full-width and halfmaximum (FWHM) value of the derivative of that curve gives an estimate of the diameter of the ion beam. Due to ion divergence, with the central electrode of the einzel lens at ground, the ion beam width is large enough to fill the $43 \mathrm{~mm}$ ID of the lens resulting in a portion of the generated MCIs hitting the einzel lens and other parts of the transport line rather than reaching the FC. Focusing the ion beam increases the total charge delivered to the FC.

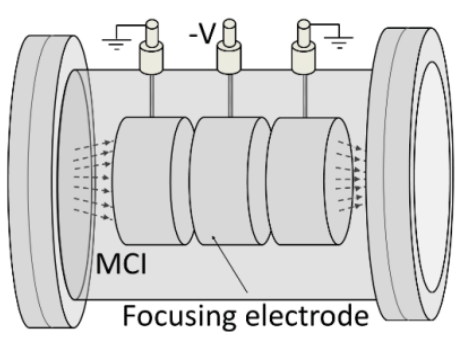


FIG 4. Schematic of the three-electrode einzel lens.

\subsubsection{Testing}

Changing the einzel lens voltage affects the total number of charge delivered to the FC. Initially with the increase of einzel lens voltage, the total charge reaching the FC increases because the electric field focuses the ion beam, reducing the ion lost in the transport line due to the divergence of the ion beam. After a certain high voltage applied to the central electrode of the einzel lens, the number of charges, with a specific charge state, delivered to the FC decreases as the ion beam is defocused at the location on the FC to an area larger than the FC diameter. The maximum charge delivered to the $\mathrm{FC}$ for $\mathrm{Al}^{1+}$ is $\sim 224 \mathrm{pC}$ at $-2.4 \mathrm{kV}$, for $\mathrm{Al}^{2+} \sim 270 \mathrm{pC}$ at $-2.2 \mathrm{kV}$, for $\mathrm{Al}^{3+} \sim 400 \mathrm{pC}$ at $-2.8 \mathrm{kV}$, and for $\mathrm{Al}^{4+} \sim 90 \mathrm{pC}$ at $-2.0 \mathrm{kV}$. The ratio of maximum charge reaching the FC and the total charge when no voltage is applied to the einzel lens is $\sim 1.5$ for $\mathrm{Al}^{1+}$, $\mathrm{Al}^{2+}$, and $\mathrm{Al}^{3+}$, while for $\mathrm{Al}^{4+}$ the ratio is $\sim 1.8$. Ion divergence from the einzel lens to $\mathrm{FC}$ is $\sim 0.5^{\circ}$ for $\mathrm{Al}^{1+}, \mathrm{Al}^{2+}, \mathrm{Al}^{3+}$ and for $\mathrm{Al}^{4+}$ the divergence is $\sim 0.75^{\circ}$ estimated by the ratio of maximum charge reaching the FC and the total charge when no einzel lens voltage is applied. At higher einzel lens voltage, the number of charges delivered to the FC is decreased. This decrease in the total charge delivered to the $\mathrm{FC}$ is because the defocused ion beam diameter at the location of the FC is increased and is larger than the FC diameter.

Fig. 5 shows measurements of the ion beam diameter at the knife edge location $(300 \mathrm{~mm}$ away from the center of the focusing lens) for different voltages applied to the einzel lens. When the central electrode of the einzel lens is grounded, the different MCIs fill the transport line and the beam diameter measured at knife edge is nearly equal to the inner diameter of the einzel lens. 
For $\mathrm{Al}^{1+}$ and $\mathrm{Al}^{2+}$, varying the einzel lens voltage from zero to $-4.0 \mathrm{kV}$ decreases the beam diameter at the knife edge. At $-4.0 \mathrm{kV}$, the ion beam diameter for $\mathrm{Al}^{1+}$ and $\mathrm{Al}^{2+}$ is $\sim 1.5 \mathrm{~mm}$, while $\mathrm{Al}^{3+}$ ion has a minimum beam diameter of $\sim 2.8 \mathrm{~mm}$ at $-3.2 \mathrm{kV}$ einzel lens voltage and $\mathrm{A} l^{4+}$ has a minimum ion beam diameter of $\sim 2.6 \mathrm{~mm}$ at $-2.7 \mathrm{kV}$. The difference in the focused beam diameter for different charge states is due to their different energy distributions and beam divergence. The inset of Fig. 5 shows the ion beam diameter for $\mathrm{Al}^{3+}$ and $\mathrm{Al}^{4+}$ for einzel lens voltage range from -2.5 to $-3.5 \mathrm{kV}$ with a step change of $100 \mathrm{~V}$. At $-4.0 \mathrm{kV}$ the ion beam diameter of $\mathrm{Al}^{3+}$ and $\mathrm{Al}^{4+}$ is increased to $\sim 11$ and $\sim 13 \mathrm{~mm}$ respectively. Due to the distance from the einzel lens to $\mathrm{FC}$ and ion beam defocusing, all the ions passing through knife do not reach the FC. When the ions are focused to minimum beam diameter at the knife edge, the number of ions reaching the $\mathrm{FC}$ for each charge state is more than $85 \%$ of their value when the ions are focused on the FC surface. This loss in the total number of ion detected when measuring the ion focus diameter by the knife edge underestimates the beam diameter at focus by $\sim 15 \%$ when assuming a Gaussian ion beam shape. The voltage applied to the einzel lens for minimum beam diameter and the resulting beam diameter depends on the charge state because the different charge states have different spatial beam divergence starting from the source [33]. Although each charge state is accelerated to a potential that is almost directly dependent on their charge state, the energy distribution of ions with different charge states vary [34]. 


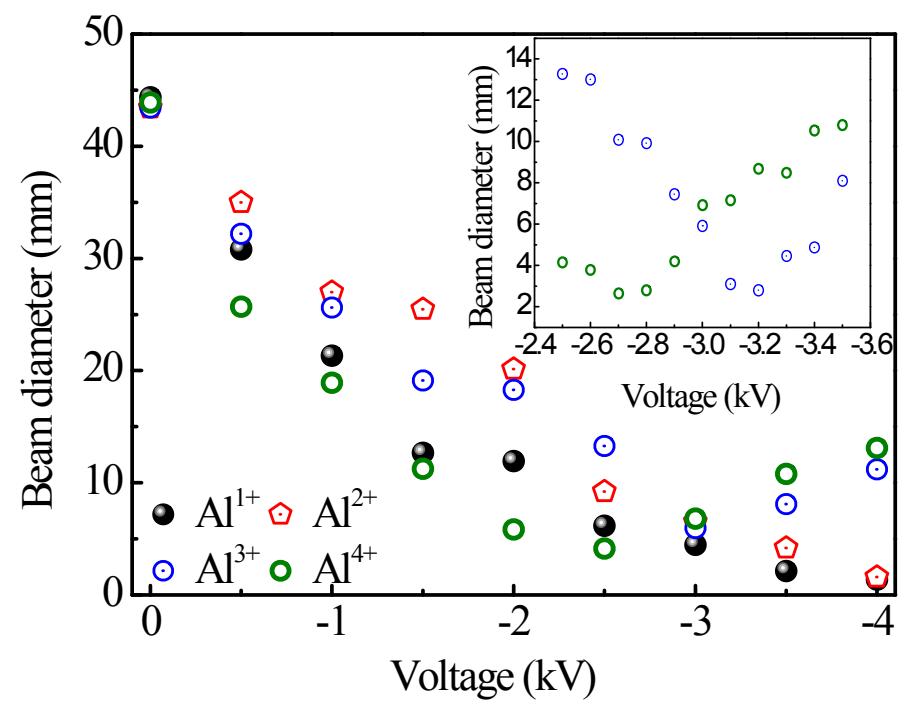

FIG. 5. Experimental results of the effect of einzel lens voltage on the beam diameter of $\mathrm{Al}^{1+}$ to $\mathrm{Al}^{4+}$ at knife edge. Inset shows beam diameter of $\mathrm{Al}^{3+}$ and $\mathrm{Al}^{4+}$ with focusing voltage in a narrow voltage region where best focus is obtained.

\subsubsection{Simulation}

SIMION 8.1 ion optics simulation software is used for the modeling of the einzel lens. SIMION uses the 3D potential array approach to estimate the electrostatic fields created by the electrode geometry. A potential array contains a collection of square mesh of points. The potential at points outside of the electrodes are determined by solving the Laplace equation via finite difference method [35]. For computation, we choose a geometry closely representing the actual experimental chamber used. The model simulates a three-electrode einzel lens with dimensions similar to our experiment. To simulate the ion source, the experimentally obtained ion divergence for each charge state and the spatial distribution (fitted with Gaussian distribution) at knife edge is used. In the SIMION model, we defined the spatial distribution of the ions with Gaussian 3D distribution with mean at origin and FWHM of $40 \mathrm{~mm}$, as calculated from the knife edge experiment. Fig. 6 shows the lens geometry and ion beam trajectories in the 
SIMION model. From the experimental results the mean energy and FWHM of the energy distribution are: $\mathrm{Al}^{1+} 2.8 \mathrm{kV}$ and $1.1 \mathrm{kV} ; \mathrm{Al}^{2+} 5.5 \mathrm{kV}$ and $1.5 \mathrm{kV} ; \mathrm{Al}^{3+} 8.2 \mathrm{kV}$ and $3.6 \mathrm{kV}$, and for $\mathrm{Al}^{4+} 11 \mathrm{kV}$ and $2.7 \mathrm{kV}$, respectively. For modeling the ion focusing distance and focus spot size, using an accurate ion energy source distribution is crucial. Fig. 7 shows the difference in ion trajectories between a cylindrical ion energy distribution (a) and a Gaussian 3D ion energy distribution when $-3.5 \mathrm{kV}$ is applied to the center electrode (b). For the cylindrical ion distribution, the $\mathrm{Al}^{4+}$ ions focus at a distance of $156 \mathrm{~mm}$ from the center electrode, while when a Gaussian ion distribution is used, that distance is $167 \mathrm{~mm}$. The minimum beam diameter for the cylindrical ion source is $1.2 \mathrm{~mm}$, whereas for the 3D Gaussian distribution it is $1.9 \mathrm{~mm}$.

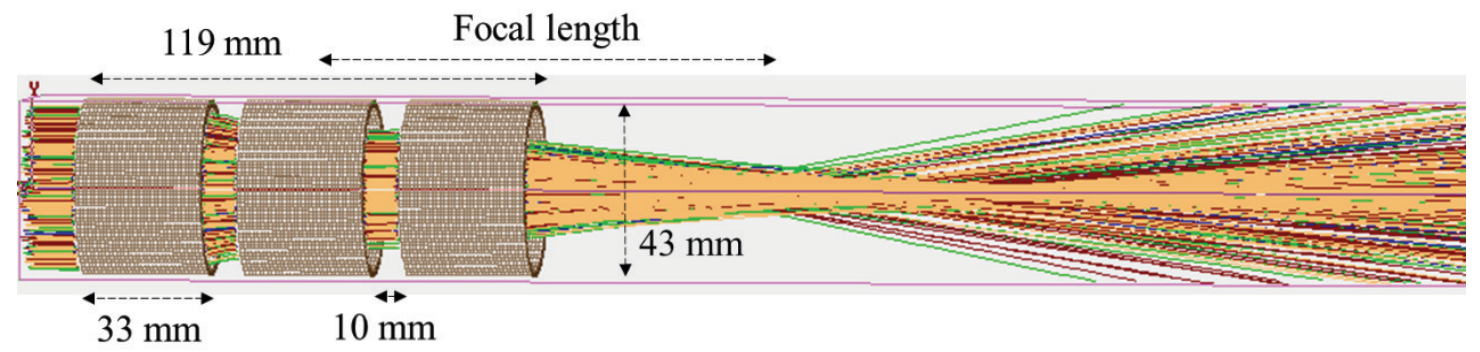

FIG. 6. SIMION simulation showing the $\mathrm{Al}^{1+}, \mathrm{Al}^{2+}, \mathrm{Al}^{3+}$, and $\mathrm{Al}^{4+}$ charges are indicated by the color blue, red, green and yellow respectively.

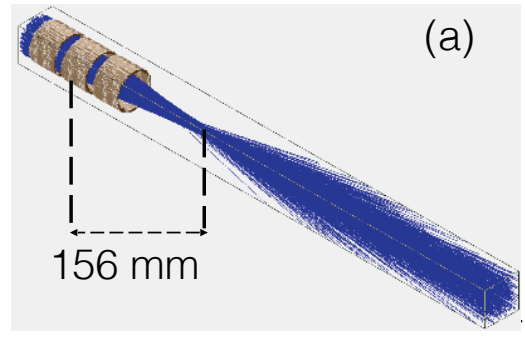




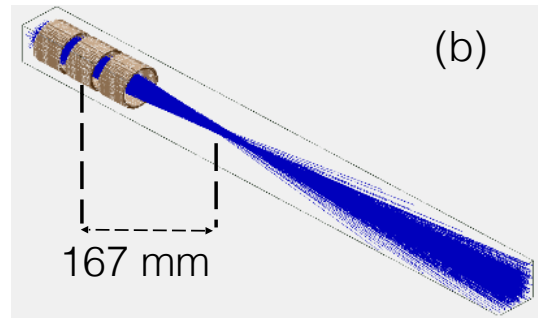

FIG. 7. Effect on ion trajectory for ion source distribution. $\mathrm{Al}^{4+}$ ions are focusing with applied voltage $-3.5 \mathrm{kV}$ with the input ions having a Gaussian energy distribution with mean of $11.5 \mathrm{kV}$ and FWHM of $2.7 \mathrm{kV}$. (a) A cylindrical spatial distribution for ion source center position at $(0,0$, 0) with radius $21 \mathrm{~mm}$. (b) Gaussian 3D spatial distribution with center at $(0,0,0)$ and FWHM of $19 \mathrm{~mm}$ on each axis.

The ion beam diameter is measured at a distance of $30 \mathrm{~cm}$ from the central electrode of the einzel lens. This distance is similar to the distance from the central electrode to the knife edge in the experiment. Fig. 8 shows simulated results for the effect of change of einzel lens voltage on the ion beam focus diameter at knife edge using SIMION. Increasing the einzel lens focusing voltage from zero to $-3.5 \mathrm{kV}$ continuously decreases the beam diameter of the ions. The minimum beam diameter for $\mathrm{Al}^{1+}, \mathrm{Al}^{2+}, \mathrm{Al}^{3+}$ and $\mathrm{Al}^{4+}$ is $\sim 2 \mathrm{~mm}$ observed for einzel lens voltage of $-2.7 \mathrm{kV}$. In the SIMION simulation, ions with different charges focus to the same beam diameter because the ions are assumed to have the same energy per charge. 


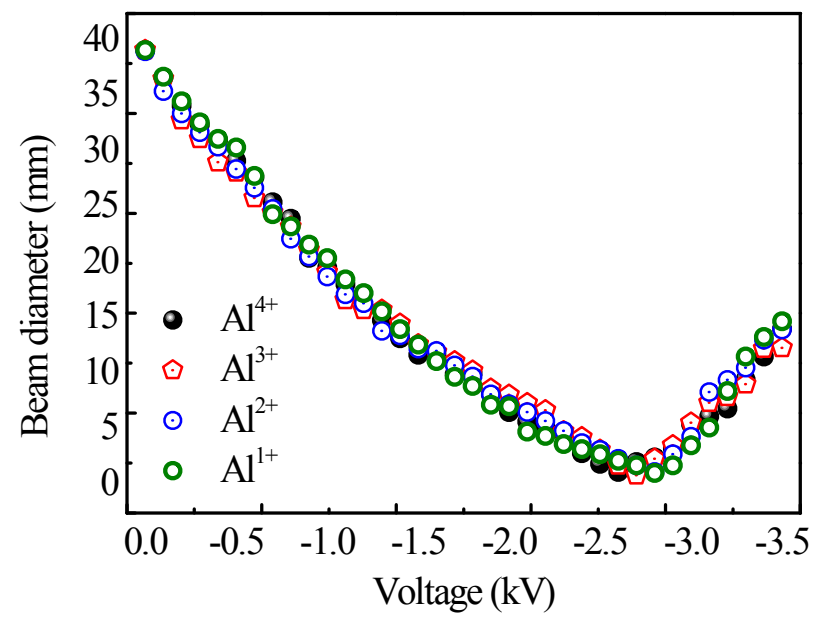

FIG. 8. Simulation of the effect of change of einzel lens voltage on (a) beam diameter of $\mathrm{Al}^{+1}$, $\mathrm{Al}^{+2}, \mathrm{Al}^{+3}, \mathrm{Al}^{+4}$ ions measured at $30 \mathrm{~cm}$ distance from the central electrode of the einzel lens.

\subsection{Ion selection}

Ion acceleration by the internal electric field generated in the plume and by the external applied electric field depends on the charge state. The higher charge states for an element are accelerated to a higher drift velocity than the lower charge states. Therefore, selection of ions with certain mass-to-charge ratio $\mathrm{m} / \mathrm{z}$ can be accomplished by applying a voltage pulse to a set of deflection plates that is synchronized to pick a subset of the ions during their TOF. Several groups reported on the use of pulsed ion deflection for selection or removal of ions with $\mathrm{m} / \mathrm{z}$. Vlasak et al., reported on the design and operation of an interleaved comb ion deflection gate device for selection of ions for particular $m / z$ for TOF mass spectroscopy [36]. With a temporary and short-range deflection field, Guilhaus et al., removed the selected ions with certain $\mathrm{m} / \mathrm{z}$ ratio from the TOF signal [37]. Toker et al., reported on a mass selection technique to clean a $\mathrm{keV}$ ion beam of undesirable ion masses using an electrostatic deflector and two grounded shielding electrodes placed before and after the electrostatic deflector [38]. A deflection device consists of 
two parallel plates for ion injection followed by two sleeve plates to reduce the ion scattering was reported [39].

We have used a pair of deflection plates to select a subset of the ions based on their TOF. For example, if one ion charge is to be selected, the deflection plates are operated to deflect the ions except the selected ion charge, which drifts to the FC. The applied voltage pulse width on the deflecting plates determines the ion pulse width reaching the FC. Therefore, it is possible to select a subset of ions that can contain more than one charge or to select a kinetic energy range of a certain charge.

\subsubsection{Fabrication}

The deflecting plates are made of aluminum and have a length of $6 \mathrm{~cm}$, width of $5 \mathrm{~cm}$, a thickness of $0.5 \mathrm{~cm}$, and are separated by $10 \mathrm{~cm}$. Insulated feedthroughs are used to mechanically support the deflection plates and apply voltage to them. One deflection plate is grounded while a voltage pulse is applied to the other plate. The location of the deflection plates in the transport line is schematically shown in Fig. 1. The distance from the Al target to the center of the deflecting plates is $\sim 120 \mathrm{~cm}$. The high-voltage pulse to select specific charge is generated using a combination of a delay generator, a high-voltage power supply, and a high-voltage pulse generator (IXYS Colorado, PVX-4110). The external trigger from the laser power supply, which controls the Q-switching of the laser, is used to trigger the pulsed delay generator, which in turn triggers the high-voltage pulse generator at a specific delay time from the laser pulse. The delay and the width of the high-voltage pulse are determined by the delay generator pulse and can be varied. We apply up to $-10 \mathrm{kV}$ pulse with variable pulse width and delay to the deflection plates. 


\subsubsection{Testing}

The vertical deflection of ions due to the electric field of the deflecting plates can be calculated from $S$, where $S$ is the deflection of ion vertically from the center of the two plates at a distance of $D$ from the end of the deflecting plates, is the deflecting voltage, is the deflecting plate length, is the separation between plates, and is the ion accelerating voltage. MCIs with different charges will be deflected together as long as they experience the same accelerating voltage (their kinetic energy is proportional to their charge). We apply $-10 \mathrm{kV}$ voltage to deflect all ions outside the Faraday cup. Then, to select $\mathrm{Al}^{1+}, \mathrm{Al}^{2+}, \mathrm{Al}^{3+}$, and $\mathrm{Al}^{4+}$, the high-voltage pulse is applied to the deflection plate at $8.0,5.8,4.5$, and $3.4 \mu$ s after the laser trigger. The energy distribution of the selected MCI depends on the selected ion pulse width. By selecting a subset of an ion charge, that energy distribution can be smaller than the distribution before the deflection plates.

Fig. 9 shows signal from $\mathrm{Al}^{1+}$ to $\mathrm{Al}^{4+}$ ions as they are picked up by the applied high-voltage pulse with a width of $1 \mu \mathrm{s}$. The TOF signal of the Al ions after charge selection with the pulsed deflection plates is shown. The inset shows the applied high-voltage pulse for selecting $\mathrm{Al}^{3+} \mathrm{MCI}$ when $7 \mathrm{kV}$ is applied to the $\mathrm{Al}$ target. The deflection plate voltage is maintained high enough to deflect all ions away from the FC. Then, a negative high-voltage pulse is applied to allow only the $\mathrm{Al}^{3+}$ ions. For example, a pulse delay by $4.5 \mu$ s to the laser trigger allows only the $\mathrm{Al}^{3+} \mathrm{MCI}$ to reach the Faraday cup. 


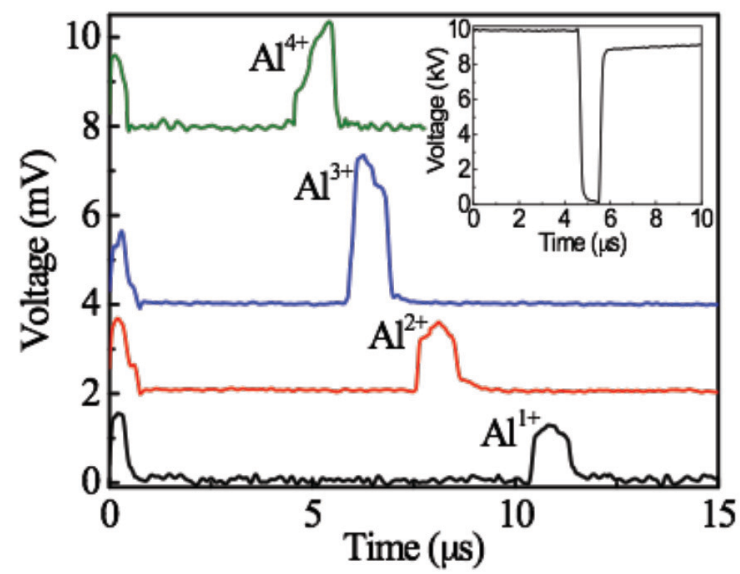

FIG. 9. Selection of MCI from $\mathrm{Al}^{1+}$ to $\mathrm{Al}^{4+}$ for deflection plate voltage $-10 \mathrm{kV}$ with pulse width 1 $\mu$ s. The delay of the deflection pulse is determined by the TOF of the ions. Inset shows the voltage pulse for selecting $\mathrm{Al}^{3+}$. Without ion selection, the TOF spectrum consists of all the MCIs generated traveling towards the FC, is shown in Fig. 2(a).

\subsection{Electrostatic ion analyzer}

Electrostatic cylindrical ion energy analyzers (EIA) are often used for analysis or selection of ions with a specified range of energy-to-charge ratio $E / z$ [40]. The EIA consists of two curved parallel plates held at different potentials and a radial cylindrical design with a deflection angle that varies depending on the application. A total deflection angle of $127^{\circ}$ is often used in energy analysis because this angle allows an ion beam focused onto the entrance slit to be also focused onto the exit slit, improving ion transmission through the EIA [41]. The EIA operated with TOF detection of MCIs allows $E / z$ ratio and $z$ to be identified independently. Therefore, the energy distribution of ions in each charge state can be obtained by applying different voltages between the EIA electrodes. An EIA was previously used to separate laser-generated MCIs and analyze their energy distribution. An EIA was used to probe Si MCIs, generated by femtosecond ablation, 
with $E / z$ of $0.4-33 \mathrm{keV}$ and energy resolution of $8 \%$ FWHM [42]. Torrisi et al., used an EIA, with $90^{\circ}$ bending angle, followed by TOF detection to study ion emission from Ta lasergenerated plasma [43]. Using a Nd:YAG laser with $270 \mathrm{~mJ} /$ pulse, they detected up to $\mathrm{Ta}^{5+}$ in the ablation plume without external ion acceleration. Mean ion energies were $250 \mathrm{eV} / z$. Shan et al., used an EIA combined with TOF detection, equipped with an electron multiplier, to probe charge state and energy distribution of the ions produced by a laser ion source [44]. Using Nd:YAG laser operating at $1064 \mathrm{~nm}$ with $8 \mathrm{~ns}$ pulse width and an energy of $1 \mathrm{~J} /$ pulse, up to $\mathrm{Al}^{12+}$ and $\mathrm{Pb}^{7+}$ were observed. We have constructed an EIA and used it to detect MCIs of Al and C.

\subsubsection{Fabrication}

The EIA is placed before the three-grid energy analyzer and Faraday cup without changing the distance from the target to the Faraday cup, as shown in Fig. 10. Ions enter the analyzer at one side and either pass through the other side or collide with the walls of the analyzer, depending on their initial kinetic energy. The ions selected by the EIA have a range of $E / z$ obtained from the equation where $E$ is the kinetic energy of the ion, $e$ is the electron charge, $U$ is the total potential across the plates, $R_{1}=145 \mathrm{~mm}$ is the inner radius, and $R_{2}=183 \mathrm{~mm}$ is the outer radius [45]. The width of the plates is $38 \mathrm{~mm}$ and the bend angle is $90^{\circ}$. Ion entrance and exit slits can be placed in the EIA to reduce the spread in $E / z$ selected, however, all results reported are without slits in order to increase ion transmission. 


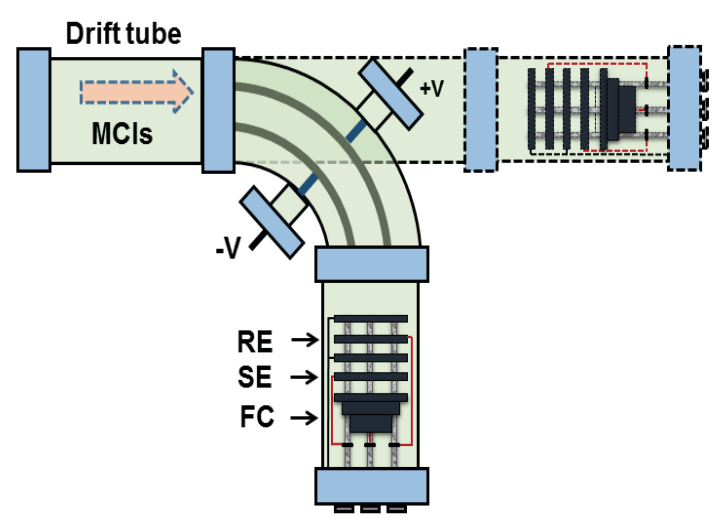

FIG. 10. Schematic of EIA analyzer and Faraday cup for ion selection with $E / z$. RE is the retarding electrodes, SE is the suppressor electrode, and FC is the Faraday cup. The system can be configured with and without the electrostatic ion energy analyzer (EIA) while maintaining the same distance between the target and the Faraday cup.

\subsubsection{Testing}

A second LMCI system is used to generate carbon MCI. In this setup, the distance from the carbon target to EIA is $90 \mathrm{~cm}$. The EIA is tested on that system and used to select carbon MCIs according to their $E / z$ ratio. The EIA spectrum is obtained at a laser energy of $34 \mathrm{~mJ}$ per pulse with an Nd:YAG laser operating at $\lambda=1064 \mathrm{~nm}$ and $\tau=7 \mathrm{~ns}$. The laser spot size at focus is $\sim 200$ $\mu \mathrm{m}$. Fig. 11 shows the carbon ion spectra for $5 \mathrm{kV}$ voltage applied to target without and with the EIA. The ion spectra in Fig. 11 is obtained when the $E / z$ selection is set to allow transmission of ions with central $E / z=2.8 \mathrm{keV}$. The voltage applied to the EIA plates are at $\pm 655 \mathrm{~V}$. Different $E / z$ selections are used to analyze the energy distribution of different MCIs. Comparison of the MCI spectra without and with the EIA shows that the carbon MCIs contain multiple peaks associated with the same ion charge. For example, the peak at $\sim 6.5 \mu$ s could be due to $\mathrm{C}^{1+}$ that is 
accelerated more than the rest of the $\mathrm{C}^{1+}$ ions by the double layer potential established in the outer layer of the expanding plasma [46].

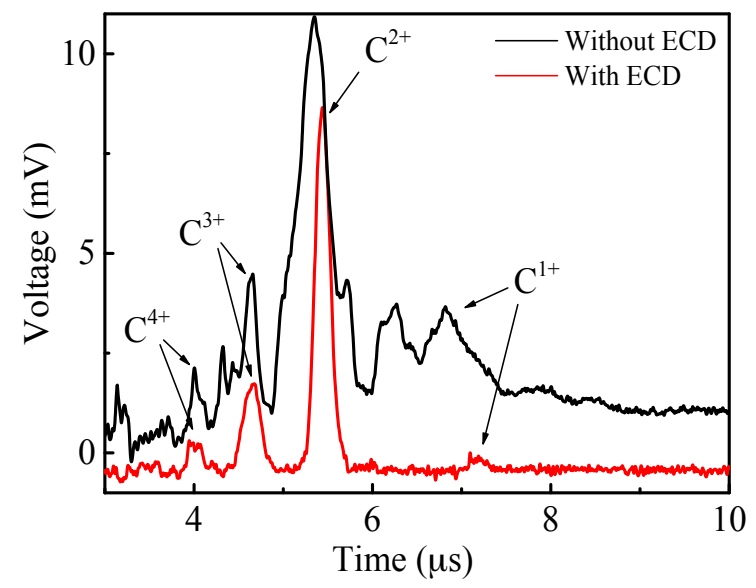

FIG. 11. Carbon ion signal detected by the Faraday cup placed without (black), and with (red, intensity $\mathrm{x} 5$ ) the electrostatic ion analyzer. The MCI signal is produced by a single pulse from a Nd:YAG laser $(\lambda=1064 \mathrm{~nm}$, pulse energy $34 \mathrm{~mJ})$. The voltage applied to target is $5 \mathrm{kV}$, and the EIA is set to central $E / z=2.8 \mathrm{keV}$.

Fig. 12 shows EIA spectrum of the $\mathrm{C}^{2+}$ and $\mathrm{C}^{3+}$ ions detected from $E / z=1.7$ to $5.1 \mathrm{keV}$. The carbon target is kept at $7 \mathrm{kV}$ acceleration voltage. The widths of $\mathrm{C}^{2+}$ and $\mathrm{C}^{3+}$ peaks before the EIA analyzer are both $\sim 3 \mu$ s. The ions have some overlap in time before deflection. Ion signals of $\mathrm{C}^{2+}$ and $\mathrm{C}^{3+}$ are shown in Fig. 12(a), and 12(b), detected for the EIA analyzer voltage set to transmit ion energies centered from 1.7 to $5.1 \mathrm{keV}$. As the EIA voltage is increased, ions with higher energies appear in the energy spectrum. The intensities of $\mathrm{C}^{2+}$ and $\mathrm{C}^{3+}$ are maximized at $E / z \sim 4.2 \mathrm{keV}$. Plasma shielding of the ions during the plume expansion in the region between the target and grounded mesh limits the ion energy gained to less than the $7 \mathrm{kV}$ voltage applied to target. Further increasing the biasing voltage up to $E / z=5.3 \mathrm{keV}$ shows the more energetic 
components of the $\mathrm{C}^{2+}$ and $\mathrm{C}^{3+}$ ions. The ion energy distributions can be reconstructed from the spectra obtained for different $E / z$ selections. The energy resolution $\Delta E / E$ of the EIA is $7-9 \%$, depending on the voltage applied across the EIA plates. The resolution is calculated by dividing FWHM of the ion peak transmitted through the EIA to the corresponding central kinetic energy of that ion. Introducing entrance and exit slits to the EIA can narrow the resolution.
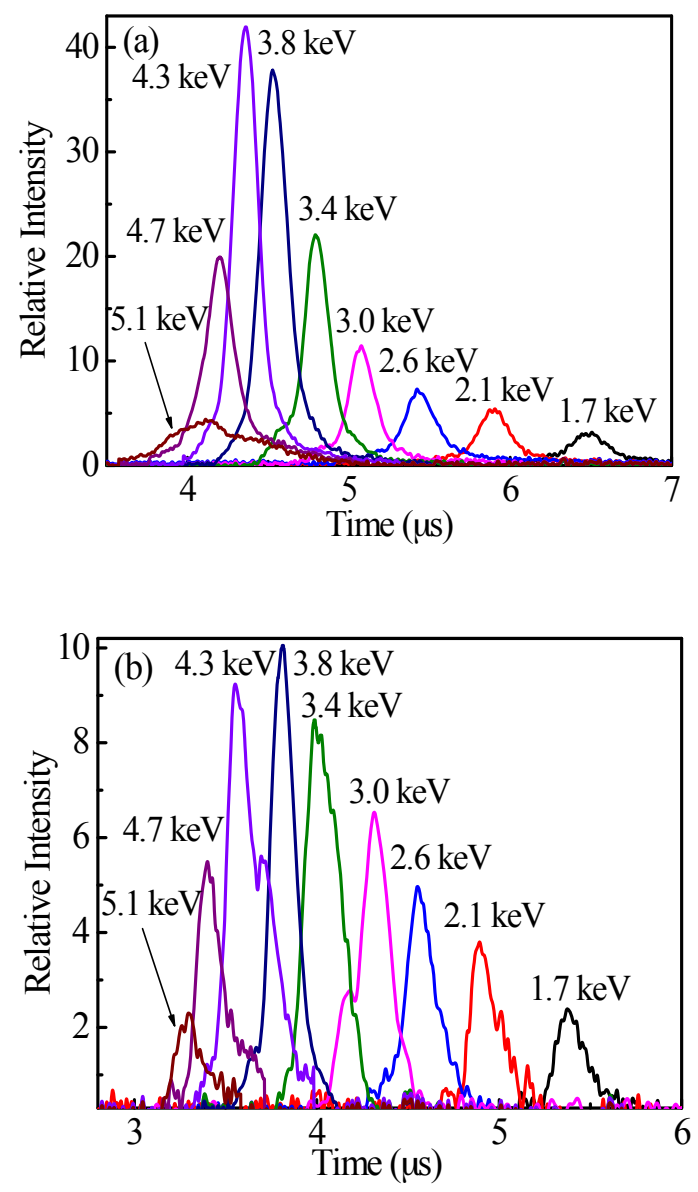

FIG. 12. EIA spectrum of $\mathrm{C}^{2+}(\mathrm{a})$ and $\mathrm{C}^{3+}$ (b) with varying $E / z$. The energy resolution $\Delta E / E$ of the EIA is $7-9 \%$, depending on the voltage applied across the EIA plates.

\subsubsection{Simulation}


SIMION is used to simulate the carbon ion trajectory in the EIA and obtain the $E / z$ selectivity of the EIA. The EIA geometry in SIMION is set similar to the experiment with the inner radius $R_{1}=145 \mathrm{~mm}$ and outer radius $R_{2}=183 \mathrm{~mm}$. The voltage across the plates is varied. The maximum number of ions detected for $\pm 500 \mathrm{~V}$ on the deflection electrodes with $E / z=2.2 \mathrm{keV}$. Fig. 13 shows the ion trajectory path for $\mathrm{C}^{4+}$ passing through the EIA and reaching the $\mathrm{FC}$ for two different voltages applied to the EIA electrodes. Fig. 14 shows the TOF spectrum in terms of the number of ions reaching the FC with $\pm 500 \mathrm{~V}$ applied on the electrodes of the EIA. From the Fig. 14, we observe that the EIA ion transmission increases with the ion charge state. The number of particles in the ion source is 500 for each charge state. All the ions are simulated with both energy distribution and special distribution obtained from the experiment. For ion energy distribution, a Gaussian three-dimensional distribution is used with a mean of 2.3, 4.2, 7 and 10.3 $\mathrm{keV}$ for $\mathrm{C}^{1+}, \mathrm{C}^{2+}, \mathrm{C}^{3+}$ and $\mathrm{C}^{4+}$, respectively. The FWHM of the Gaussian energy distribution is $1.5,2.9,3.8$, and $4.3 \mathrm{keV}$ for $\mathrm{C}^{1+}, \mathrm{C}^{2+}, \mathrm{C}^{3+}$ and $\mathrm{C}^{4+}$, respectively. The simulated $\mathrm{TOF}$ corresponding to peak signal for $\mathrm{C}^{1+}, \mathrm{C}^{2+}, \mathrm{C}^{3+}$ and $\mathrm{C}^{4+}$ are $7.9,5.5,4.6$, and $3.9 \mu \mathrm{s}$, respectively, whereas, the experimental TOF is 7.2, 5.4, 4.6, and $4 \mu \mathrm{s}$ as shown in Fig. 11.

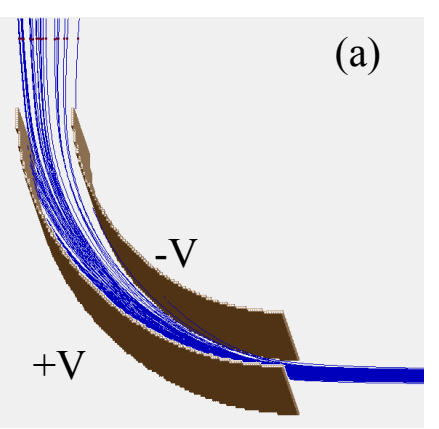




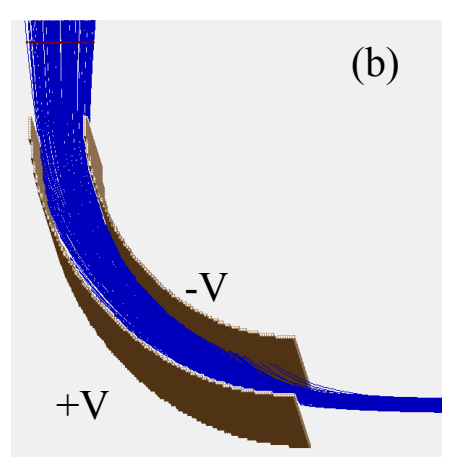

FIG. 13. Ion trajectory path for $\mathrm{C}^{4+}$ through the EIA. The applied voltage to the EIA (a) $\pm 500 \mathrm{~V}$, (b) $\pm 300 \mathrm{~V}$.

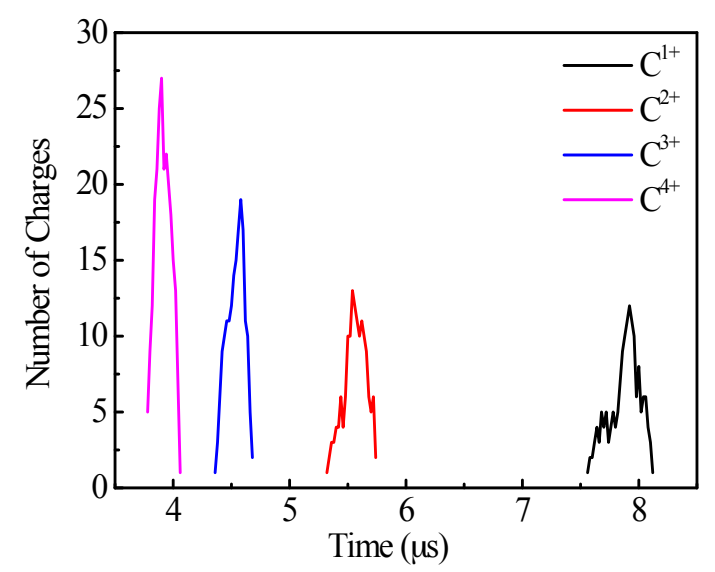

FIG. 14. Simulated TOF spectrum for $\mathrm{C}^{1+}, \mathrm{C}^{2+}, \mathrm{C}^{3+}$, and $\mathrm{C}^{4+}$. The applied voltage to the EIA is $\pm 500 \mathrm{~V}$.

\section{CONCLUSION}

Components of a transport line for a LMCI source are constructed and tested. These components are an einzel lens for ion focusing, parallel deflection plates with pulsed voltage source for MCI charge selection, electrostatic cylindrical ion energy analyzer for $\mathrm{MCI} E / z$ selection, three-grid ion energy analyzer, and a Faraday cup for TOF ion detection. We are able to focus the ion beam down to $\sim 1.5 \mathrm{~mm}$ depending on ion charge. Ion pick-up from TOF with 
variable pulse width allows for selecting an ion charge and a narrow energy distribution of the selected charge if the pick-up pulse is shortened below the ion pulse width. Ion selection by pulsed deflection plates can be used for ion pick-up in tandem TOF instruments and avoids transport of contamination ions produced from the target surface during laser-target interaction. A high voltage pulse generator with programmable narrow pulse width is necessary for the ion selection. The EIA combined with TOF measurement are used to resolve both $E / z$ and ion charge and obtain the energy distribution of each charge. The overall energy resolution of the EIA for the carbon $\mathrm{MCI}$ is $7-9 \%$. This resolution can be reduced by using input and output slits. The transport line components discussed are all built on standard ConFlat flanges making them highly modular. This design provides the flexibility to modify each component, reconfigure the transport line, and add other beam forming and beam steering components in addition to a substrate processing chamber.

\section{Acknowledgements}

This material is based upon work supported by the National Science Foundation, USA, under Grant No. MRI-1228228.

\section{REFERENCES}

[1] J. D. Gillaspy, J. M. Pomeroy, A. C. Perrella, and H. Grube, "The potential of highly charged ion: possible future applications", In Journal of Physics: Conference Series, IOP Publishing 58 (2007) 451

[2] H. Gnaser, Low-Energy Ion Irradiation of Solid Surface, edited by G. Hohler, Springer Tracts in Modern Physics Vol. 146 (Springer, Berlin, Heidelberg, New York, 1999) 
[3] J. D. Gillaspy, "highly charged ions", J. Phys. B: At. Mol. Opt. Phys. 34 (2001) R93.

[4] A. C. Villari, "Latest trends in ECR technology and Pantechnik ECRIS", In Proceedings of the DAE-BRNS Indian particle accelerator conference, 2011.

[5] G. Zschornack, M. Kreller, V. P. Ovsyannikov, F. Grossman, U. Kentsch, M. Schmidt, F. Ullmann, and R. Heller, "Compact electron beam ion sources/traps: Review and prospects (invited) a)", Rev. Sci. Instrum. 79 (2008) 02A703.

[6] B Ilyas, A H Dogar, S Ullah and A Qayyum, "Laser fluence effects on ion emission from a laser-generated Cu plasma”, J. Phys. D: Appl. Phys. 44 (2011) 295202.

[7] H. Daido, M. Nishiuchi, and A. S. Pirozhkov, "Review of laser-driven ion sources and their applications", Rep. Prog. Phys. 75 (2012) 056401.

[8] A. Lorusso, L. Velardi, V. Nassisi, F. Paladini, A. M. Visco, N. Campo, L. Torrisi, D. Margarone, L. Giuffrida, and A. Rainò, "Polymer processing by a low energy ion accelerator”, Nucl. Instrum. Methods Phys. Res. Sect. B 266 (2008) 2490.

[9] B. Y. Sharkov, S. Kondrashev, I. Roudskoy, S. Savin, A. Shumshurov, H. Haseroth, H. Kugler, K. Langbein, N. Lisi, H. Magnusson, and R. Scrivens, "Laser ion source for heavy ion synchrotrons", Rev. Sci. Instrum. 69 (1998) 1035.

[10] M. Trinczek, A. Werdich, V. Mironov, P. Guo, A.J. González Martínez, J. Braun, J.R. Crespo López-Urrutia, J. Ullrich, "A laser ion source for an electron beam ion trap", Nucl. Instrum. Methods Phys. Res. Sect. B 251 (2006) 289.

[11] P. Yeates, J. T. Costello, and E. T. Kennedy, “The DCU laser ion source”, Rev. Sci. Instrum. $81(2010) 043305$. 
[12] T. Nagaya, T. Nishiokada, S. Hagino, T. Uchida, M. Muramatsu, T. Otsuka, F. Sato, A. Kitagawa, Y. Kato, and Y. Yoshida, "Producing multicharged fullerene ion beam extracted from the second stage of tandem-type ECRIS", Rev. Sci. Instrum. 87 (2016) $02 \mathrm{~A} 723$.

[13] M. H. A. Shaim, and H. E. Elsayed-Ali, “Aluminum multicharged ion generation from laser plasma", Nucl. Instrum. Methods Phys. Res. Sect. B 356 (2015) 75.

[14] M. H. A. Shaim, and H. E. Elsayed-Ali, "Spark discharge coupled laser multicharged ion source”, Rev. Sci. Instrum. 86 (2015) 073304.

[15] S. Prasad, K. Tang, D. Manura, D. Papanastasiou, and R. D. Smith, "Simulation of ion motion in FAIMS through combined use of SIMION and modified SDS", Anal. Chem. 81 (2009) 8749 .

[16] N. S. Saks, A. K. Agarwal, S. H. Ryu, and J. W. Palmour, "Low-dose aluminum and boron implants in 4H and 6H silicon carbide”, J. Appl. Phys. 90 (2001) 2796.

[17] B. Sharkov, and R. Scrivens, "Laser ion sources”, IEEE Trans. plasma sci. 33 (2005) 1778.

[18] V. Gordienko, I. Lachko, A. Rusanov, A. Savel'Ev, D. Uryupina, and R. Volkov. "Enhanced production of fast multi-charged ions from plasmas formed at cleaned surface by femtosecond laser pulse", Appl. Phys. B 80 (2005) 733.

[19] R. Volkov, V. Gordienko, I. Lachko, A. Rusanov, A. Savel'ev, and D. Uryupina. "Formation of fast multicharged heavy ions under the action of a superintense femtosecond laser pulse on the cleaned surface of a target", J.Exp.Theor. Phys. 103 (2006) 303.

[20] V. Nassissi, A. Pedone, A. Rainò, "Preliminary experimental results on an excimer laser ion source", Nucl. Instr. Meth. B 188 (2002) 267. 
[21] D. Doria, A. Lorusso, F. Belloni, Nassisi, L. Torrisi, S. Gammino, "A study of the parameters of particles ejected from a laser plasma”, Laser Part. Beams 22 (2004) 461.

[22] O. Balki, and H. E. Elsayed-Ali. "Multicharged carbon ion generation from laser plasma", Rev. Sci.c Instrum. 87 (2016) 113304.

[23] W. Lu, C. Qian, L. T. Sun, X. Z. Zhang, X. Fang, J. W. Guo, Y. Yang, Y. C. Feng, B. H. Ma, B. Xiong, L. Ruan, H. W. Zhao, W. L. Zhan, and D. Xie, "High intensity high charge state ion beam production with an evaporative cooling magnet ECRIS", Rev. Sci. Instrum. 87 (2016) 02A738.

[24] L. Sun, J. Guo, W. Lu, W. Zhang, Y. Feng, Y. Yang, C. Qian,X. Fang, H. Ma, X. Zhang, and H. Zhao, "Advancement of highly charged ion beam production by superconducting ECR ion source SECRAL”, Rev. Sci. Instrum. 87(2016) 02A707.

[25] Ady I. Hershcovitch, "Eliminating unwanted electrons in EBIS devices", Rev. Sci. Instrum. 87 (2016) 02A918.

[26] S. Schwarz and A. Lapierre, "Recent charge-breeding developments with EBIS/T devices", Rev. Sci. Instrum. 87 (2016) 02A910.

[27] H. Kashiwagi, M. Fukuda, M. Okamura, R. A. Jameson, T. Hattori, N. Hayashizaki, K. Sakakibara, J. Takano, K. Yamamoto, Y. Iwata, and T. Fujimoto, “Acceleration of high current fully stripped carbon ion beam by direct injection scheme”, Rev. Sci. Instrum. 77 (2006) 03B305.

[28] D. W. Heddle, Electrostatic lens systems. CRC Press, Institute of Physics publishing, Bristol and Philadelphia (2000). 
[29] O. Sise, M. Ulu, and M. Dogan, "Multi-element cylindrical electrostatic lens systems for focusing and controlling charged particles", Nucl. Instrum. Methods Phys. Res. Sect. A $554(2005) 114$.

[30] O. Sise, M. Ulu, and M. Dogan, "Characterization and modeling of multi-element electrostatic lens systems", Radiat. Phys. Chem. 76 (2007) 593.

[31] M. M. Abdelrahman, "Ion Beam Simulation Using a Three-Electrode Diaphragm Einzel Lens System“, J. Nucl. Radiation Phys. 3 (2008) 93.

[32] M. H. Rashid, "Simple analytical method to design electrostatic einzel lens", In Proceedings of the DAE Symp. on Nucl. Phys, vol. 56 (2011) 1132.

[33] A. Thum-Jaeger, B. K. Sinha, and K. P. Rohr, “Time of flight measurements on ion-velocity distribution and anisotropy of ion temperatures in laser plasmas", Phys. Rev. E. 63 (2000) 016405.

[34] L. Torrisi, S. Gammino, L. Andò, V. Nassisi, D. Doria, and A. Pedone, "Comparison of nanosecond laser ablation at 1064 and 308 nm wavelength”, Appl. Surf. Sci. 210 (2003) 262.

[35] D. A. Dahl, J. E. Delmore, and A. D. Appelhans, "SIMION PC/PS2 electrostatic lens design program”, Rev. Sci. Instrum. 61 (1990) 607.

[36] P. R. Vlasak, D. J. Beussman, M. R. Davenport, and C. G. Enke, “An interleaved comb ion deflection gate for $\mathrm{m} / \mathrm{z}$ selection in time-of-flight mass spectrometry", Rev. Sci. Instrum. 67 (1996) 68.

[37] M. Guilhaus, Spectochim, "Essential elements of time-of-flight mass spectrometry in combination with the inductively coupled plasma ion source", Acta B 55 (2000) 1511. 
[38] Y. Toker, N. Altstein, O. Aviv, M. L. Rappaport, O. Heber, D. Schwalm, D. Strasser, and D. Zajfman, "The kick-out mass selection technique for ions stored in an Electrostatic Ion Beam Trap”, J. Instrum. 4 (2009) P09001.

[39] D. Wayne, and J. Olivares, "Selective removal of matrix ion peaks in plasma source time-offlight mass spectrometry: ion deflection and detector gating", J. Anal. At. Spectrom. 14 (1999) 1523.

[40] L. Torrisi, D. Mascali, R. Miracoli, S. Gammino, N. Gambino, L. Giuffrida, and D. Margarone, "Measurements of electron energy distribution in tantalum laser-generated plasma”, J. Appl. Phys. 107 (2010) 123303.

[41] D. P. Hale, and W. D. Allen, "An electrostatic electron energy analyser for 3-20 keV electrons", J. Phys. E 4 (1971) 311.

[42] V. M. Gordienko, I. M. Lachko, A. A. Rusanov, A. B. Savel'Ev, D. S. Uryupina, and R. V. Volkov, "Enhanced production of fast multi-charged ions from plasmas formed at cleaned surface by femtosecond laser pulse“, Appl. Phys. B 80 (2005) 733.

[43] L. Torrisi, F. Caridi, D. Margarone, and A. Borrielli, "Plasma-laser characterization by electrostatic mass quadrupole analyzer", Nucl. Instrum. Methods Phys. Res. Sect. B 266 (2008) 308 .

[44] S. Shan, J. Qian-Yu, L. Zhang-Min, G. Xiao-Hong, Z. Lun-Cai, C. Guo-Zhu, S. Liang-Ting, Z. Xue-Zhen, Z. Huan-Yu, C. Xi-Meng, and Z. hong-Wei, "Charge state distribution analysis of $\mathrm{Al}$ and $\mathrm{Pb}$ ions from the laser ion source at IMP”, Chin. Phys. C 37 (2013) 117006. 
[45] E. Woryna, P. Parys, J. Wołowski, and W. Mroz, "Corpuscular diagnostics and processing methods applied in investigations of laser-produced plasma as a source of highly ionized ions", Laser Part. Beams 14 (1996) 293.

[46] N. M. Bulgakova, A. V. Bulgakov, and O. F. Bobrenok, "Double layer effects in laserablation plasma plumes", Phys. Rev. E 62 (2000) 5624. 